\title{
A Gestão de Design humanizada pelo Design thinking a partir de relações conceituais
}

The Design Management humanized by the design thinking throughout conceptual relations

\author{
DEMARCHI, Ana Paula Perfetto; Doutora; Universidade Estadual de Londrina - UEL \\ perfeto@sercomtel.com.br
}

FORNASIER, Cleuza Bittencourt Ribas; Doutora; Universidade Estadual de Londrina - UEL fornasier@gmail.com

MARTINS, Rosane Fonseca de Freitas; Doutora; Universidade Estadual de Londrina - UEL rosane@uel.br

\begin{abstract}
Resumo
O objetivo deste artigo é apontar os aspectos históricos da Gestão de Design por meio das suas características de atuação na sociedade, pelos diferentes rumos que esta tomou enfatizando as conceituações de design, a caracterização e evolução histórica que proporcionou, até a formulação conceitual do design operacional (relativo ao fazer) e estratégico (relativo ao planejar). Como metodologia, empregou-se a pesquisa de natureza exploratória de dados primários. Como resultado apresenta-se a influência da sua formação sobre os rumos que a gestão de design tem tomado no Brasil, e a importância estratégica de que essa se una ao conceito de design thinking, se caracterizando assim como uma gestão humanistica.
\end{abstract}

Palavras Chave: Gestão de design; Design thinking; Visão humanística do design.

\begin{abstract}
The aim of this paper is to point out the Design Management's historical aspects through its modes of action in society, the different paths that took emphasizing the design concepts, characterization, and historical evolution that has provided to the formulation of the conceptual operational design (relative to do) and strategic (relative to plan). The methodology used to study was of the exploratory nature of primary data. The result shows the knowledge influence on the direction that design management has taken in Brazil, and the strategic importance that this join to the concept of design thinking, characterizing it as a humanistic management.
\end{abstract}

Keywords: Design management; Design thinking; Humanistic vision of design.

\section{Introdução}

O tem sido propagado na literatura, no Brasil e no exterior, como sendo uma ferramenta estratégica de desenvolvimento econômico e de competitividade, no entanto, ainda ocorre a resistência da utilização do design e dos designers nas empresas brasileiras, mesmo que seja apenas para desenvolver os aspectos estéticos dos produtos, fase já ultrapassada em muitos países. Na mesma relação está a gestão de design, que também deveria estar contribuindo para um melhor desempenho do design nas organizações, porém, no Brasil, não está corrente

Projética Revista Científica de Design I Universidade Estadual de Londrina I V.2 I N.1 I Junho 2011 
Ana Paula Perfetto Demarchi; Cleuza Bittencourt Ribas Fornasier; Rosane Fonseca de Freitas Martins esta aplicação e o gestor de design, quando inserido na organização, continua agindo de forma operacional em vez de agir de forma estratégica, o que deixa longe a incorporação da cultura de design na organização.

Para Mozota (2003), e Joseph (2003), a Gestão de Design vem acompanhando as evoluções da gestão, que consolidou-se em um modelo taylorista e por muito tempo, evoluiu centrada nos conceitos da gestão tradicional. O problema atual da Gestão de Design consiste na necessidade adequar-se a sociedade complexa, e para isso, deve se tornar flexível e ancorar a tomada de decisões de risco, ser autônoma, orientada ao usuário, ajudando a mudança da cultura organizacional. As organizações brasileiras ainda estão no primeiro modelo, pois são raras as organizações que possuem estrutura flexível e fácil adaptabilidade para incorporar progressivamente a cultura de design.

Portanto, o objetivo deste artigo é apontar os aspectos históricos da Gestão de Design por meio das suas características de atuação na sociedade, pelos diferentes rumos que esta tomou enfatizando as conceituações de design, a caracterização e evolução histórica que proporcionou, até a formulação conceitual do design operacional (relativo ao fazer) e estratégico (relativo ao planejar). Como metodologia, empregou-se a pesquisa de natureza exploratória de dados primários.

\section{Evolução histórica do Design}

Gestão de design é o gerenciamento do design, de acordo com Best (2006). No senso mais básico, a gestão de design é o gerenciamento do processo de design. Para alguns o trabalho do gestor de design fica restrito ao projeto, para outros, no entanto, a abordagem de gestão de design migrou para abordagens mais amplas. Para compreender a gestão de design, a qual, segundo COTEC (2008, p.70), tem como missão "criar e dinamizar a relação entre design e as outras áreas da organização", deve-se compreender o design e toda a sua trajetória na história.

Design representa tanto o processo de fazer alguma coisa, como o produto desse processo. O termo design está sendo muito utilizado no século XXI, no entanto, não é uma atividade nova, começou a se desenvolver no Brasil em 1950, quando a palavra design passou a ser associada à preocupação apenas com as propriedades formais dos objetos e à estética dos produtos, já que as próprias definições tradicionais da atividade do design enfatizam esses aspectos.

A exploração das diferentes fases da história do design auxilia na compreensão dos valores básicos que envolvem a área do design, valores estes que as organizações, atualmente, querem integrar nos seus sistemas gerenciais. Pode-se dizer que o design existe desde os primórdios da humanidade, quando o homem, para suprir suas necessidades básicas criou produtos. A pré-história do design situa-se na Inglaterra com a emergência da padronização da produção. Foi quando houve a dissociação da concepção do objeto de sua manufatura, que até então, estava incorporado às habilidades de um indivíduo, o artesão (MOZOTA, 2003).

A mecanização imposta pela Revolução Industrial possibilitou a reprodução, em série, de artigos úteis e baratos. Como relata Hosbsbawm (1982, p.69), para os comerciantes, a "única lei era comprar no mercado mais barato e vender sem restrição no mais caro". Em vista disso, e por ser a mão-de-obra despreparada e mal-remunerada, os produtos não tinham qualidade.

A Grande Exposição dos Trabalhos de Indústria de Todas as Nações de 1851, no Palácio de Cristal $^{1}$, em Londres, conhecida como Exposição Internacional, baseou-se na crença, cultivada pelo sonho burguês, da "verdade universal, num sistema social hegemônico" (BARBUY,1999,

Projética Revista Científica de Design I Universidade Estadual de Londrina I V.2 I N.1 I Junho 2011 
Gestão de Design humanizada pelo Design thinking a partir de relações conceituais p.30). Difundia um estilo de vida e de progresso diferentes, propondo um novo conceito de sociedade e cultura. Muito mais que uma mostra de produtos comerciais, disseminava uma educação doutrinária por meio da apresentação real das novas propostas, que, segundo Denis (2000), difundia o hábito do olhar como estímulo ao consumo.

Essas novas propostas eram consideradas, por muitos, como loucuras estéticas, consequências da produção em série das grandes indústrias. Denis (2000), Bürdek (1999), Pevsner (1995) e Droste (1994) atribuem ao educador, historiador e filósofo inglês John Ruskin, a luta contra a produção industrial dos objetos. De acordo com Heskett (1998), Ruskin afirmava que os produtos simples e utilitários concebidos faziam parte da cultura materialista e dos processos de produção em massa, diferentes, portanto, dos produtos europeus baseados nas tradições artesanais. Segundo Denis (2000), esta crítica era voltada contra a falta de qualidade, e contra a falta de arte e de estética, vício que marginalizava o trabalhador, desqualificando-o sistematicamente e levando-o a uma participação apenas pontual na fabrição do produto.

Por este motivo, apareceram algumas Guilds ${ }^{2}$ de artesãos que pretendiam lutar contra o declínio moral da sociedade. A primeira foi a Guild of Saint George fundada por John Ruskin, que "acreditava que um artefato é uma entidade abstrata, o resultado de um processo complexo composto de circunstâncias sociais e econômicas, relações com clientes, e métodos de execução que determinam o produto final" (MOZOTA, 2003, p.22).

Ruskin lutava pela manutenção do artesão. Unindo-se a sindicalistas, afirmava que "o problema do design residia não no estilo dos objetos, mas no bem-estar do trabalhador" (DENIS, 2000, p.71). Ruskin foi, também, um dos primeiros defensores da qualidade total. Para Moralles, "a maior contribuição de Ruskin consistiu em assinalar a responsabilidade social do designer e a repercussão do design na cultura" (COSTA, 2002, p.14).

Segundo Mozota (2003), a cadeira de Michael Thonet (fig. 1), concebida em 1859, foi o primeiro exemplo de transferência de conhecimento e técnicas inovadoras de outro campo do conhecimento para o design. Na intenção de padronizar este movimento inicial aboliu-se a beleza do objeto feito pelo artesão, dando-se lugar à tecnologia. O diferencial deste produto é o processo de fabricação inovador (não a sua forma), ao moldar barras e pranchas de madeira maciça por aquecimento, permitindo sua produção em série a baixos custos. Foi, também, o primeiro mobiliário na história a ser produzido, e entregue completamente desmontado.

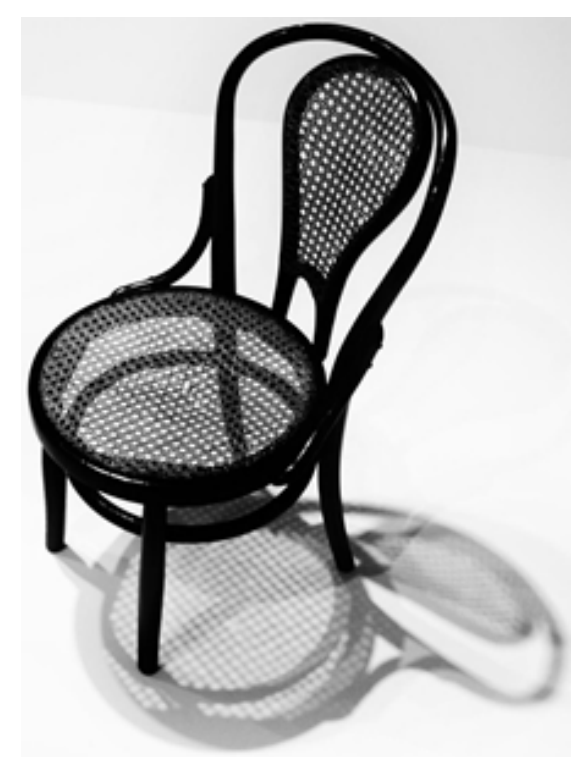

Figura 1- Cadeira de Thonet, modelo 214

Fonte: Thonet Chair (2011); ANTAR (2011) 
Ana Paula Perfetto Demarchi; Cleuza Bittencourt Ribas Fornasier; Rosane Fonseca de Freitas Martins

Segundo Pevsner $(1995$, p.6), William Morris, designer e escritor, foi um dos primeiros a entender que "os fundamentos sociais da arte tinham ficado mais inconsistentes com a revolução industrial" e que é impraticável a separação de "arte, moral, política e religião". De acordo com Denis (2000), Morris, seguindo as ideias de Ruskin, seu mestre, funda a primeira unidade de produção inspirada no princípio organizador do design da Morris \& Company, de 1875. Integrando projeto e execução, buscava autonomia com flexibilização na produção e na comercialização. Mozota (2003) afirma que Morris produziu pela primeira vez artefatos que combinavam forma, função e decoração. Muitos dos produtos podiam ser executados artesanalmente, outros com limitada mecanização e outros projetados pela Morris e Co., mas eram executados por terceiros, e primavam pela qualidade, não pela quantidade. No entanto, "a unidade da produção advinha essencialmente do design, o estilo Morris foi aos poucos ficando conhecido do público, projetando o designer para uma posição de destaque na valorização da mercadoria" (DENIS, 2000, p.73).

Morris funda o movimento Arts and Crafts, o primeiro movimento opositor à industrialização, cuja filosofia "girava em torno da recuperação dos valores produtivos tradicionais defendidos por Ruskin" (DENIS, 2000, p.73). Para Bürdek (1999), era um movimento de reforma social e de inovação de estilo. Segundo Niemeyer (1997), o movimento foi decisivo para o futuro do design, e para Pevsner $(1995$, p.8), contribuiu "para uma renovação do artesanato artístico e, não das artes industriais", uma vez que "os integrantes do movimento buscavam promover uma maior integração entre projeto e execução, uma relação mais igualitária e democrática entre os trabalhadores envolvidos na produção [...]" (DENIS, 2000, p. 75).

No final do século XIX, as preocupações sociais e ambientais eram defendidas por muito poucos. Assim, Morris foi derrotado pela força econômica que comandava a industrialização. Nessa época, a preocupação era aliar arte e indústria, e procurar dar beleza aos produtos fabricados em série.

Segundo Heskett (1998), o arquiteto americano Frank Lloyd Wright proferiu uma palestra, The Art and Craft of the Machine, em 1901, na qual Wright rejeitava a produção artesanal por ser dispendiosa, apoiava a mecanização com preocupação estética e condenava a má utilização do potencial produtor, que copiava formas de culturas passadas e acreditava que a máquina emancipava a mente moderna, lançando, com isso, os primeiros sinais para a formação do Movimento Modernista. Argumentava que "a perspectiva de uma vida melhor para todos e a diminuição do trabalho pesado humano eram essenciais para o florescimento de uma cultura democrática" (HESKETT, 1998, p.44). "[...] o mal que a máquina faz ao artesanato poderá ser precisamente aquilo que virá libertar os artistas [...]" (PEVSNER, 1995, p. 17).

Bürdek (1999) e Denis (2000) relatam que em diferentes países surgem novas manifestações imortalizadas pelo senso artístico e artesanal, que pode ser generalizado pela denominação Art Nouveau, derivada do nome da loja do negociante de arte Samuel Bing, L'Art Nouveau (TAMBINI, 1997), de Paris, ao qual Ribeiro (1985) atribui, como características gerais, o ritmo delicado de linhas ondulantes e a predominância da ornamentação floral, com unidade de estilo e, portanto, abrangendo todas as áreas decorativas e estruturais de um local. Bürdek (1999) atribui a Henry Van de Velde, o maior expoente do movimento, a valorização do artesanato, sem as mesmas aspirações que as de Morris, pois defendia o trabalho único e a consciência de que o artesanato só poderia ser usado pela elite, já que o custo ficava inacessível às outras camadas. Este movimento está sempre associado ao luxo.

Opondo-se a L'Art Nouveau e sucedendo-a, de acordo com Denis (2000), aparece o Art Déco, com espírito modernista. Suas características estão associadas ao geométrico, à sobreposição de planos e ao mecanicismo, originando a produção em massa de vários artigos

Projética Revista Científica de Design I Universidade Estadual de Londrina I V.2 I N.1 I Junho 2011 
decorativos.

Gestão de Design humanizada pelo Design thinking a partir de relações conceituais

Anos depois, na Alemanha, por meio dos fundamentos estéticos criados pelo prussiano Hermann Muthesius, e de acordo com Niemeyer (1997), Shulmann (1994) e Bürdek (1999), fundou-se, em 1907, a Deutscher Werkbund. Era uma associação de artistas, mestres de oficinas, artesãos e industriais dedicados a desenvolver a aliança entre arte, indústria e artesanato, com o intuito de criar estilos mais simples voltados à produção industrial de qualidade. Este movimento formalizou o profissional de design, introduziu a característica de estandardização e presenciou a integração da arte com a indústria. O processo educativo e formativo, apresentado e difundido na época, colocava o design "como elemento fundamental para a expansão da economia nacional e a restauração da cultura alemã" (NIEMEYER,1997, p.37). Pevsner (1995) relata que a máquina e o homem devem entrar em sintonia, desde que este domine aquela, e faça dela sua ferramenta de trabalho realizando produtos de qualidade. O movimento apontou a ineficiência das empresas no dever de servir à comunidade e no direcionamento das atividades do design industrial.

De acordo com Niemeyer (1997), Bürdek (1999) e Shulmann (1994), um dos primeiros membros da Werkbund foi Peter Behrens, considerado o primeiro designer, por ter realizado um projeto de design global $^{3}$ para a fábrica de eletrodomésticos alemã Allgemeinen Elektricitats Gesellschaft (AEG), ou seja, realizou o projeto arquitetônico da fábrica à imagem visual, incluindo o projeto gráfico de seus catálogos e mostruários. De acordo com Mozota (2003), esta experiência única e inovadora foi o primeiro exemplo de uma abordagem global de consistência visual de uma organização (fig.2).

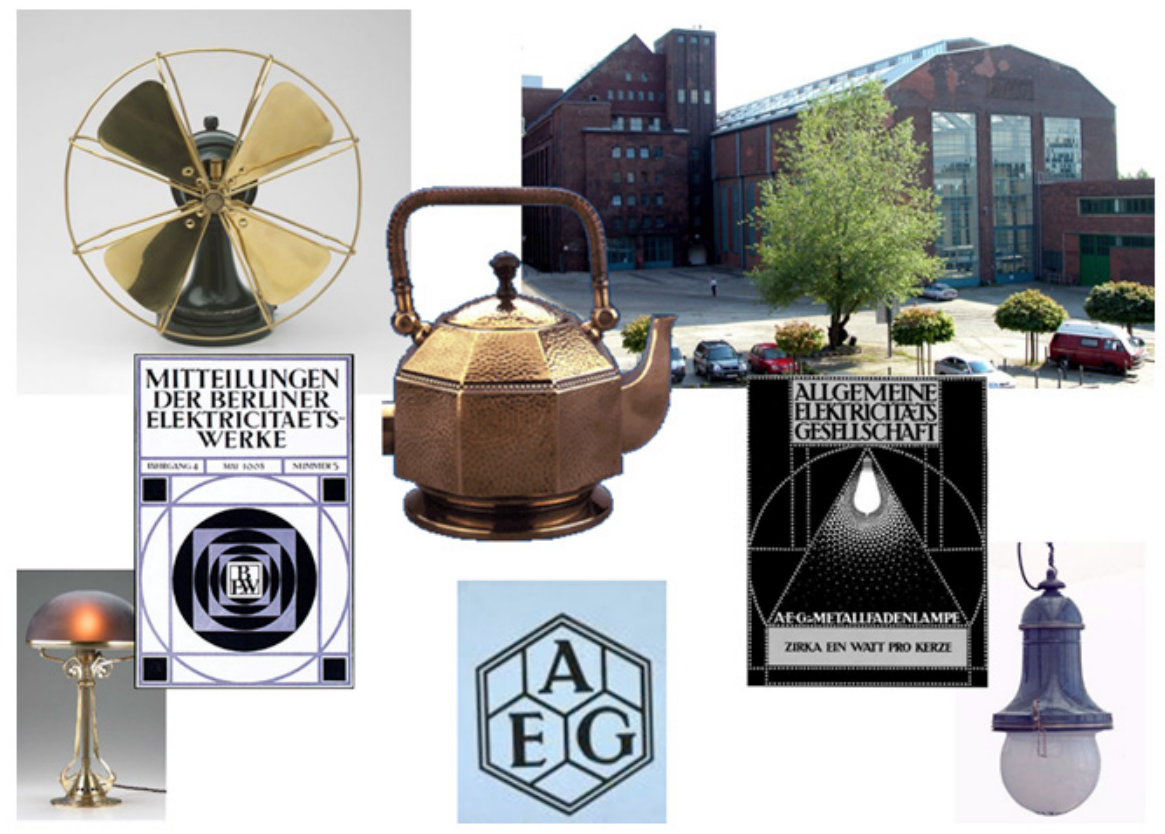

Figura 2- Projeto de Design total de Peter Behrens para AEG

Fonte: Enciclopédia Britannica (2010); Quarante (1992).

Na mesma época, Henry Ford implantava sua nova forma de produção nos Estados Unidos da América, como o fez também o engenheiro Frederick Taylor. Ambos criaram métodos de padronização de trabalho, levando a uma "rejeição completa do conceito artesanal de trabalho, que depende da perícia, julgamento e responsabilidade dos indivíduos" (HESKETT, 1998, p.66).

Ambos criaram o sistema de produção em massa, que introduz os conceitos de padronização e racionalização, de que resulta a diminuição da mão-de-obra qualificada.

Projética Revista Científica de Design I Universidade Estadual de Londrina I V.2 I N.1 I Junho 2011 
Ana Paula Perfetto Demarchi; Cleuza Bittencourt Ribas Fornasier; Rosane Fonseca de Freitas Martins Introduzem o conceito de fluxo contínuo da produção, por força do qual, as funções dos operários são "subdivididas e reduzidas aos seus elementos essenciais, permitindo a extrema especialização de tarefas simples e monótonas que podiam ser repetidas incessantemente e com grande rapidez" (DENIS, 2000, p. 103), o que exige do operário um ritmo insuportável de trabalho, razão da desqualificação.

Para Azevedo (1991), após um século, surge o conceito do homem moderno e a necessidade de romper com o passado. São feitos questionamentos sobre o novo mundo da indústria e criam-se diversos movimentos que influenciam o design. Modernamente, a atividade do designer não concebe o trabalho individual. O design é essencialmente uma profissão de cunho interdisciplinar e que ocupa seu lugar em organizações assumindo diversas responsabilidades na adaptação de produtos realizados em série.

$\mathrm{Na}$ passagem do sistema artesanal para o industrial, o design sofre influências de diversos movimentos, como o Arts and Crafts e o Werkbund. Entretanto, é na Bauhaus que a ideia de transformar o artesão em produtor em série encontra sua maior expressão, com projetos desprovidos de ornamentos e de fácil execução pela máquina.

A Bauhaus foi uma escola pioneira do design fundada em 1919 por Walter Gropius, em Weimar, Alemanha, que defendia a ideia de que a arte poderia ser funcional, ou seja, a forma é definida pela função. Passou por Dessau e Berlim, onde funcionou até 1933, quando foi fechada pelo governo nazista. Segundo Droste (1994), sem estilo, o estilo Bauhaus transformou-se num conceito, num chavão internacional, que ainda hoje exerce influências no que tange ao seu processo histórico (décadas de 60 e 70) tanto nas áreas de trabalho e oficinas, quanto (recentemente) nas investigações críticas.

A Bauhaus seguia a tônica a forma segue a função, o que, segundo Bahiana (1998), significa que aquilo que é projetado, do ponto de vista funcional, acaba tendo uma forma agradável, atraindo as pessoas. A escola exercia influências em áreas distintas do design. $\mathrm{Na}$ verdade, pretendia criar um profissional completo, um profissional da forma, que estudava desde fundamentos da arte e composição, até inúmeras oficinas de ofícios e arquitetura. Entretanto, seus reflexos ultrapassam estas definições simplistas, culminando num grandioso aspecto social.

[A Bauhaus] Tornou-se a abreviatura da modernização radical da vida e dos seus efeitos secundários, positivos e negativos. O nome representava todo um programa; o desenvolvimento e os destinos plenos de vicissitudes da Escola foram, com uma atitude aprovadora ou não, largamente aceita (DROSTE, 1994, p.6).

Ludwig Mies Van der Rohe, seu último diretor, dissolveu a escola de Berlim em 1933, pouco depois da tomada de poder pelos nacionalista-socialistas e sob sua forte pressão. No entanto, Mozota (2003) afirma que esta filosofia foi transportada para os Estados Unidos, para onde muitos dos fundadores da Bauhaus emigraram, incluindo Walter Gropius (em 1933). Sua influência propagou-se para além da Bauhaus, por meio de seus ensinamentos na Universidade de Harvard e na Nova Bauhaus em Chicago, e culminou no desenvolvimento da cultura da Arquitetura Vertical Americana, a qual privilegiava o conhecimento científico e lutava contra os ornamentos, consolidando assim o pensamento modernista centrado na razão.

Segundo Mozota (2003), o design tornou-se profissão nos Estados Unidos em 1930. No contexto da crise econômica de 29, manufaturas rapidamente tornaram-se cientes do papel do design de produto no sucesso comercial. Os primeiros designers são consultores autônomos, criavam com finalidade comercial, permitindo a convergência entre o industrial e o criador, que adaptava a forma à moda vigente. $A$ isso se denomina styling (que projeta apenas a forma final do produto), ou seja, o estilo, duramente criticado pelos designers. Diferentemente da Bauhaus, que criava produtos para a indústria sem referência no mercado, o styling americano

Projética Revista Científica de Design I Universidade Estadual de Londrina I V.2 I N.1 I Junho 2011 
Gestão de Design humanizada pelo Design thinking a partir de relações conceituais considera design como um esforço do grupo que objetiva relançar produtos criando uma forma mais ajustada às necessidades do consumidor. Os designers, não contentes em redesenhar os produtos existentes, desenvolvem um estilo denominado Streamlining. Trata-se da apropriação da aerodinâmica utilizada nas formas da aviação comercial e de suas adaptações a outros setores; suas formas arredondadas refletem dinamismo, modernidade, síntese estética e tecnológica, e conquista a simpatia do consumidor.

Foi também, por volta de 1930 que, segundo Mozota (2003), o primeiro sistema de identificação visual apareceu. $\mathrm{O}$ grafismo do metrô de Londres, originariamente desenvolvido em 1916 e revisado sob a direção de Frank Pick, desde 1933 unificou o visual do metrô. Esta ação iniciou o debate cultural na área do design, entre os adeptos de um design racional e funcionalista e os adeptos do simbolismo (a aparência de formas livres), que origina um confronto internacional a partir da década de 50. A estética neo-acadêmica não se justificava para produtos de grande consumo, para os quais se buscava uma estética transitória fundada nos símbolos da época. A Bauhaus e o Styling formaram os pioneiros dos designers autodidatas (arquitetos e artistas), que estenderam suas influências para a indústria e o mercado de outros países. Instaurou-se, no Brasil, a formação acadêmica entre os anos 50s e 60s, o que explicaria a diversidade de currículos do curso de Design cuja formação pode estar voltada às artes, ou à escola politécnica, e à diversidade dos conceitos e aplicações do design.

No entanto, em 1981 segundo Mozota (2003), com o surgimento do movimento Memphis, um grupo de designers italianos celebrou o declínio do dogma funcionalista em suas estéticas, privilegiando o símbolo sobre a função. Outros movimentos na França (Totem) e na Inglaterra (NATO) tiveram a mesma abordagem, retornando à ênfase dada ao ornamento, abaixo a figura 3 sintetiza essa evolução histórica.

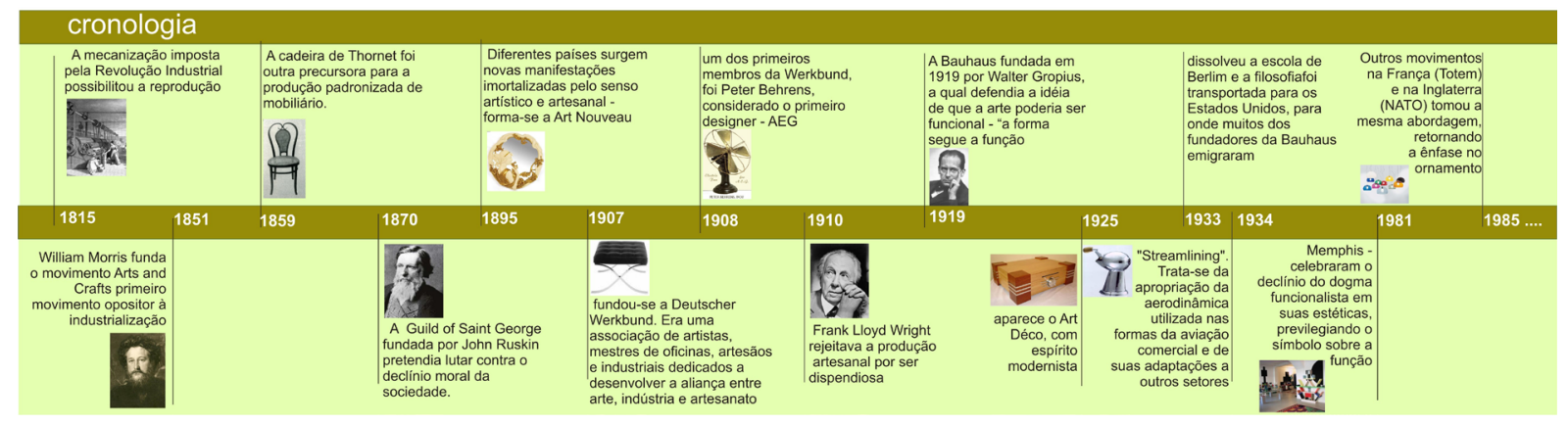

Figura 3- Evolução histórica do design

Fonte: Demarchi (2011)

A maior evolução desde 1990 tem sido a relação entre design e tecnologia. O designer pode, agora, trabalhar com a aparência externa sem ser controlado pela sua estrutura interna. "Design, arte e artesanato têm muito em comum e hoje, quando o design já atingiu certa maturidade institucional, muitos designers começam a perceber o valor de resgatar as antigas relações como o fazer manual" (DENNIS, 2000, p.17). Segundo a conceituação tradicional, o design difere do artesanato pelo fato de que o designer projeta e o artesão produz mecanicamente, de preferência produzindo em série. Esta é uma das primeiras definições do design, cujo termo foi, primeiramente, utilizado no século 17, registrado no Oxford English Dictionary.

\section{Caracterização do Design}


Durante o modelo modernista, conclui-se que o design é um processo, e que para tanto precisa ser gerenciado. Portanto, a gestão de design nasce, na prática, no meio de um modelo modernista.

Para que se possa escrever sobre a gestão de design é importante entender, além de sua evolução histórica, a sua etimologia. Niemeyer (1997) diz que a palavra inglesa design deriva do verbo latino designo, cujo sentido é designar, indicar, representar, marcar, ordenar, regular. Design significa projeto, configuração, distinguindo-se da palavra drawing - desenho, representação de formas por meio de linha e sombra. Essa distinção também ocorre no espanhol, porém, não no português.

De acordo com Struck (2007, p.16), "o filósofo Antonio Houaiss uma vez sugeriu que fosse utilizado projética, no entanto o termo não foi bem aceito e assim durante anos permaneceu a expressão desenho industrial". Contudo, isso gerou uma série de equívocos, pois desenho refere-se a um meio de expressão e não à concepção, e quando se coloca a palavra industrial possibilita-se confundi-la com desenho técnico. Convem lembrar que, na época de sua inserção no Brasil, a terminologia em inglês era proibida.

Não é só a confusão da terminologia que gera dúvida na área do design. Conforme pesquisa realizada por Geraldine Witter, "Desenho Industrial é atividade científica de projetar, integrando várias áreas de conhecimento, estabelecendo relações múltiplas, para a solução de problemas de produção de objetos que tem por alvo final atender as necessidades do homem e da comunidade" (NIEMEYER, 1997, p.23)

Todavia, as primeiras conceituações de design o modelam como ferramenta operacional, sem dar-se ênfase ao seu caráter estratégico. Como exemplo, pode-se citar Maldonado que, na década de 80 , define design como

uma atividade de projeto que consiste em determinar as propriedades formais dos objetos a serem produzidos industrialmente. Por propriedades formais entendemse não só as características exteriores, mas, sobretudo, as relações estruturais e funcionais do objeto. (MAGALHAES, 1997, p.18)

Este conceito continuou em exercício no Brasil até meados do ano 2000, apesar da literatura nacional pregar práticas mais reflexivas, o que retardou as ações sistêmicas que o design vem realizando em outras culturas.

O Internacional Council of Societies of Industrial Design (Icsid), por sua vez, dá esta definição:

O Design é uma atividade criativa cujo alvo seja estabelecer as qualidades multidisciplinares dos objetos, dos processos, dos serviços e dos seus sistemas em ciclos de vida inteiros. Conseqüentemente, o design é o fator central da humanização inovativa das tecnologias e o fator crucial da troca cultural e econômica. (Icsid, outubro 2006)

De acordo com Mozota (2003), a vantagem desta definição é que ela evita a armadilha de ver o design somente sob a perspectiva de resultado (o estético e a aparência), mas enfatiza noções de criatividade, consistência, qualidade industrial e forma.

Outra definição traz o campo do design mais próximo da indústria e do mercado:

o serviço profissional de criação e desenvolvimento de conceitos e especificações otimiza a função, valor, e aparência dos produtos e sistemas de benefícios mútuos de ambos, usuários e manufatura. (MOZOTA, 2003, p.3). 
Esta definição insiste na capacidade do designer de gerar sinergia entre o mundo industrial, o tecnológico, e o mundo dos consumidores. Cabe lembrar que o designer não trabalha sozinho e necessita de outras áreas para concluir na íntegra um projeto.

A dificuldade já começa na própria delimitação profissional; no entanto, novos autores sabem da importância do pensar estrategicamente. Schulmann (1994, p.34) diz "ser um criador industrial implica, portanto, na necessidade de saber organizar os dados de uma nova maneira, de ter aptidão de sair dos esquemas analíticos tradicionais."

Portanto, mais do que a criação de novos produtos, a profissão de designer compatibiliza, também, os fatores ligados às técnicas, ao planejamento e aos fatores humanos para a resolução de problemas; por isso, a formação em design em um âmbito mais completo seria essencial.

$\mathrm{Na}$ visão empresarial, a novidade, segundo Deschamps e Nayak (1997, p.39), é a percepção de que:

- Design vai além do estilo;

- Design está se tornando crítico para um número cada vez maior de indústrias;

- Design transmite qualidade e aumenta a margem de lucro; e

- Design pode e precisa ser administrado.

O design não é somente estilo ou adição externa de um toque estético ao produto, pelo contrário, um bom profissional tem como objetivo realçar a experiência física e funcional do consumidor durante a vida útil daquilo que comprou. Os japoneses chamam esta experiência de humanware, a arte e ciência de projetar produtos para pessoas. (MUNARI, 1975).

No entanto, a profissão de design, além de considerar o consumidor, ocorre a cobrança em relação à criatividade, que é inerente a profissão, pois é ela que projeta coisas criativas. Os empresários e industriais perceberam a questão da globalização mercadológica inserida neste contexto, assim, estão preocupados com a concorrência e já começaram a enxergar no design um fator de distinção de seus produtos, ou seja, almejam realizar produtos que se diferenciem pela criatividade em algum âmbito.

O designer industrial pode ser considerado como produtor de idéias, recolhendo informações e utilizando-as na solução de problemas que lhe são apresentados. Além de sua capacidade intelectual, i.e., capacidade de reunir informações e utilizálos em diversas situações, ele deve possuir capacidade criativa. (LÖBACH, 2000 p.139).

Ainda de acordo com Löbach (2000), a criatividade do designer se manifesta quando este, baseando-se em seus conhecimentos e experiências, for capaz de associar determinadas informações com um problema, estabelecendo novas relações entre elas. A originalidade do designer, para conceber produtos inéditos, deve-se à necessidade cada vez maior da inovação como arma poderosa para um mercado competitivo.

Magalhães (1997) foca duas concepções do design com vista à inovação. O design europeu, altamente intelectualizado e voltado à simplicidade funcional, foca o trabalho de dentro para fora da empresa, e o design americano, considerado como ferramenta de estilo, no qual o exterior é tudo que importa, assim desenvolvem o projeto de fora para dentro, ou seja, o desenvolvimento é baseado no mercado. Outras referências que podem ser apontadas são também o design asiático, no qual o Japão é referência em Design centrado na qualidade e a Coréia é referência em Design centrado no conhecimento e inovação. 

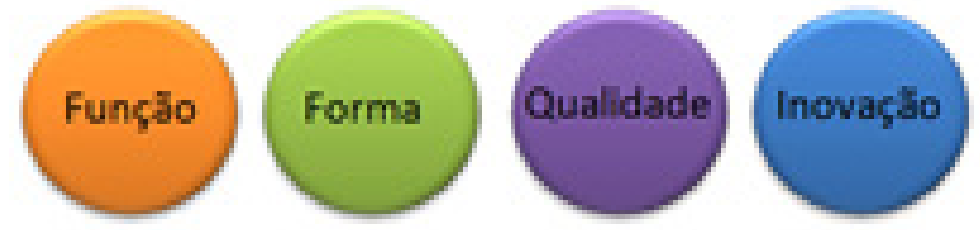

A Forma e a Função são ligadas, primeiramente, ao desenvolvimento do produto. Efatiza-se que no design europeu, "o bom design", empenhava-se em mudar a qualidade de vida das pessoas, ao que hoje se denomina design social, e no design americano a forma do produto tinha a função de divulgação e venda sem a preocupação social. Já a Qualidade e a Inovação são ligadas à organização de uma maneira macro, ou seja, aos aspectos estratégicos. Nesse sentido, será abordado a seguir, a construção dos conceitos de design operacional e estratégico.

\section{Do Design Operacional ao Design Estratégico}

Os métodos de design atualmente difundidos estão voltados para um design operacional, pois enfatizam o planejamento e o controle do processo relacionado com as tarefas internas de desenvolvimento de produto propriamente ditas, oferecendo-se pouco instrumental para atuação do designer voltado para a integração profissional da cultura de design nas empresas.

Observa-se, então, que mais do que a criação de novos produtos, a profissão de design compatibiliza não só os fatores ligados às técnicas, mas principalmente, os ligados ao planejamento, aos fatores humanos para a resolução de problemas e para verificação de oportunidades de negócios, caracterizando uma distinta forma de pensar o design, como ferramenta estratégica ou, como é mais conhecido, o design estratégico.

De acordo com Magalhães (1995, p.22), o designer permanece "sem ferramentas e conhecimentos para desenvolver uma política estratégica para o design em empresas que demandem por ela". A empresa hoje precisa de um profissional que atue de forma estratégica. 0 designer, para estar compatível com este mercado e deve completar sua formação operacional, com uma estratégica.

Segundo Magalhães (1997, p.26), "O design pode ser utilizado como um processo de catalisação (sic), sintetização e materialização de conhecimentos e informações em produtos e serviços. O design estratégico materializa-se quando o importante é desenvolver o produto certo - eficácia do processo de design - e não somente desenvolver corretamente o produto eficiência no processo de design".

Design estratégico pode ser entendido, então, como o estágio no qual os projetos de design são concebidos e cujo foco está na identificação e criação de condições para que ferramentas de design possam ser propostas e promovidas (BEST, 2006). Este estágio é responsável por identificar oportunidades que facilitem ao designer entender o público-alvo e o mercado, interpretar o cliente/consumidor e suas necessidades, e propor estratégias que deem suporte para a realização das metas da organização, além de comunicá-las.

Conforme Magalhães (1997), entende-se por design estratégico "uma forma de atuação deste profissional direcionada para a gestão do design nas empresas, ou seja, ocupandose da orientação da política do design, apoiado por análises de fatores internos e externos às empresas, em um nível hierárquico mais alto dentro destas e desde as primeiras fases do desenvolvimento de produtos". Para tanto, o design deve estar inserido na estratégia empresarial. 
Gestão de Design humanizada pelo Design thinking a partir de relações conceituais Gillespie (2002) afirma que no contexto organizacional "estratégia e design são atividades globais da empresa".o design é tido como uma força de integração entre todas as ferramentas da empresa e deve trabalhar próximo principalmente do marketing e da engenharia, além de estar em contato com os clientes e tecnologia, propondo uma estrutura de ação estratégica do design. $\mathrm{O}$ quadro abaixo resume as diferenças entre a visão do design operacional e do design estratégico.

\begin{tabular}{|l|l|}
\hline Design operacional & Design estrátégico \\
\hline $\begin{array}{l}\text { Ação a partir de uma proposta } \\
\text { inicial }\end{array}$ & $\begin{array}{l}\text { Ação em que se participa do inicio do } \\
\text { desenvolvimento do produto, participando } \\
\text { da conceituação do produto, junto com as } \\
\text { demais áreas envolvidas neste processo. }\end{array}$ \\
\hline $\begin{array}{l}\text { Ação isolada de outras áreas, buscando-se } \\
\text { uma habilitação específica }\end{array}$ & $\begin{array}{l}\text { Ação catalizadora de conhecimentos } \\
\text { envolvidos no processo, assumindo-se a } \\
\text { interdiciplinaridade }\end{array}$ \\
\hline Pensamento fracionado & Pensamento global \\
\hline Eficiência do design & Eficácia do design (além da eficiência) \\
\hline Desenvolvimento correto do produto & Desenvolver o produto certo \\
\hline $\begin{array}{l}\text { Ênfase nas necessidades do usuário do } \\
\text { produto }\end{array}$ & $\begin{array}{l}\text { Énfase nas necessidades, desejos e } \\
\text { conveniências do beneficiário do produto } \\
\text { (incluindo-se consumidor, usuário, } \\
\text { fabricante e sociedade), tendo-se os } \\
\text { concorrentes como referência }\end{array}$ \\
\hline $\begin{array}{l}\text { Solução dos problemas físicos dos } \\
\text { produtos }\end{array}$ & $\begin{array}{l}\text { Monitoramento dos problemas e } \\
\text { prospecção das oportunidades }\end{array}$ \\
\hline $\begin{array}{l}\text { Erocesso de dentro para fora do produto, } \\
\text { A forma segue a função na solução de problemas }\end{array}$ & $\begin{array}{l}\text { Processo de fora para dentro do produto, } \\
\text { A forma segue a mensagem (o que o } \\
\text { público percebe) }\end{array}$ \\
\hline $\begin{array}{l}\text { através da especificação de atributos } \\
\text { fícos }\end{array}$ \\
\hline
\end{tabular}

Quadro 1- Quadro comparativo design estratégico e design operacional Fonte: Magalhães (1995, p.25)

A partir do quadro 1 conclui-se que a premissa da Bauhaus - a "forma segue a função" - é uma herança das bases conceituais do design, na qual foi fundado o ensino de design no Brasil. No entanto, o que se espera é que os designers passem a trabalhar a partir da nova premissa, a "forma segue a função de comunicar", na qual é fundado o design estratégico.

Nessa premissa, a mensagem comunicada pelos designers fazem parte dos benefícios do produto, esperados pelos consumidores.

Para Martin (2009, p.58), "design não é somente fazer coisas bonitas; é também fazer com que as coisas trabalhem maravilhosamente bem", é, portanto, trabalhar com o design estratégico. Para o autor, design é fazer com que o conhecimento obtido passe no funil do conhecimento, resultando num resultado único e possível dado o momento e a tecnologia disponível; para ele, design é uma atividade de design thinking, portanto, para haver o design deve haver anteriormente o design thinking.

$\mathrm{Na}$ definição mais popular, "design thinking significar pensar como um design faria" (MARTIN, 2009, p.62). Tim Brown, da Ideo, define o design thinking 
como a disciplina que utiliza a sensibilidade do designer e métodos para atingir as necessidades das pessoas com o que tecnologicamente factível e o que a viável estratégia de negócio possa converter em valores para o consumidor e oportunidade de mercado (apud MARTIN, 2009, p.62).

Chohan (2008) sugere que as empresas buscam o design thinking pela maneira de aplicar métodos de design em diferentes situações da vida. Este pensamento captura e provoca diferentes maneiras de ver coisas e modular situações. Design thinking é adicionar mais criatividade, não para aumentá-la, mas para clarificar e focalizar as tomadas de decisões criativas nos processos sistêmicos associados aos designers. O design thinking difere de outras maneiras de pensar, pois tem uma abordagem mais arriscada e experimental, permitindo que os indivíduos modelem livremente as idéias.

Segundo Martin (2009), a organização que utiliza o design thinking aplica a ferramenta mais crucial do designer em problemas de negócios. Esta ferramenta é o raciocínio abdutivo.

A maioria das pessoas é exposta a lógica formal por inferência, e somente pelas duas formas dominantes de raciocínio: o dedutivo e o indutivo.

- O dedutivo - a lógica do que deve ser - razão do geral, para o específico; e

- O indutivo - a lógica do que é operativo - razão do específico para o geral.

Para Peirce (apud MARTIN, 2009), novas ideias não são produto das duas formas aceitas de lógica. Para ele, novas ideias surgem por "saltos lógicos da mente". Peirce explicava que novas ideias surgem quando um pensador observa dados que não se ajustam com o modelo existente. O pensador busca sentido na observação fazendo o que o autor chama de "inferência para a melhor explicação" (apud MARTIN, 2009, p.64). Os designers vivem no mundo de abduções de Peirce, eles ativamente olham para novos pontos de vista dos dados, desafiam explicações aceitas e inferem novos mundos possíveis.

Para Marco Steinberg (apud LOCKWOOD, 2006, p.83), a diferença entre design operacional e design estratégico é que o primeiro dá "sentido a objetos; e design estratégico é dar sentido a decisões". Portanto, se o design thinking é aplicar a sensibilidade e métodos do designer para solucionar problemas da organização, o design estratégico necessita do design thinking para dar sentido a suas decisões criativas. Para Lockwood (2006), o design estratégico pode ser compreendido com o resultado da gestão de design.

\section{A Gestão de Design}

Segundo Best (2006), a gestão do processo de design é somente um aspecto da gestão de design. A atividade de design é centrada no usuário e é um processo de solução de problema, que também precisa ser gerenciado e, portanto, dela surge outra faceta da gestão de design.

Os termos gestão e gerenciamento são frequentemente utilizados como sinônimos. Apesar de semanticamente terem a mesma raiz, no mundo dos negócios têm significados bem diferentes.

O termo 'gerenciamento' remete á função de monitoramento e controle do recurso gerência, enquanto a gestão é mais abrangente e compreende: planejamento, projeto, construção, implementação, utilização, monitoramento, identificação de melhorias e realização de ajustes (DE SORDI, 2005, p. 23) 
Gestão de Design humanizada pelo Design thinking a partir de relações conceituais

A gestão de design insere-se na mudança do modelo hierárquico, modelo gerencial de Taylor, para o modelo organizacional horizontal e flexível, o qual encoraja iniciativas individuais, independentes, e a assunção de riscos.

A origem da gestão de design remonta aos anos 60, na Inglaterra, época em que a expressão significava a gestão da interface entre um escritório de design e seus clientes. Michael Farr, em 1966, preconizava uma nova função de "gerenciamento pelo Design", cuja missão seria de assegurar uma condução eficaz dos projetos e de estabelecer uma boa comunicação entre o escritório e seus clientes (MOZOTA, 2003). Considerava, ainda, que esta atividade podia ser exercida por um gerente da empresa cliente, pois o mais importante era a finalidade, ou seja, uma boa comunicação.

É, então, na Inglaterra que surge a consciência do papel que o design pode exercer sobre a economia e as empresas, segundo Hetzel ${ }^{4}$ (1993, apud MOZOTA, 2003), com a ação conjunta do Royal College of Arts, de Londres e do departamento de Design Management, da London Business School, dirigida por Peter Gorb.

Segundo Bürdek (1999), Schulmann (1994) e Wallace (2002), em 1907, o arquiteto Peter Behrens, um dos primeiros membros da Werkbund, comandava (como diretor-artístico) a Allgemeinen Elektricitats Gesellschaft (AEG), desenhando todos os seus produtos, fábrica, habitações para funcionários, identidade e desenhos publicitários. Foi o primeiro "designer corporativo", ou a considerar a projeção da imagem sobre o público. Acredita-se ter nascido aí a Gestão de Design.

Mozota (2003) relata que, em 1975, Bill Hannon e o Massachusetts College of Art fundaram, em Boston, o Design Management Institute (DMI) que tinha como objetivo treinar parceiros gerentes e designers no intuito de familiarizar designers com a gestão e gerentes com o design, bem como desenvolver métodos para integrar o design no ambiente organizacional.

Peter Gorb, em 1990, define gestão de design como "O efetivo desdobramento pelos gerentes de linha dos recursos de design disponíveis para a empresa a fim de ajudar a empresa em atingir seus objetivos" (MOZOTA, 2003, p.70).

Patrick Hetzel, em 1993, amplia o escopo da gestão do design, quando o define como:

- Gerenciar design, no qual ocorre o gerenciamento do processo criativo através da empresa;

- Gerenciar uma empresa de acordo com os principio de design ;e

- Gerenciar uma firma de design

Para Mozota (2003, p. 71), gestão de design

é a implementação do design como um programa formal de atividades dentro da empresa pela comunicação da relevância do design para as metas organizacionais de longo termo e coordenar recursos de design ao nível de atividade empresarial para atingir objetivos organizacionais.

Esta é uma definição com foco na gestão estratégica de design. Já Earl Power afirma:

a gestão de design ocupa-se do desenvolvimento, organização, planejamento e controle dos recursos relacionados ao uso humano dos produtos, comunicações e ambientes (apud PHILLIPS, 2008, p.107).

Best (2006, p. 6) define gestão de design como "o papel de liderança, que requer explicar, inspirar, persuadir e demonstrar como o design pode positivamente contribuir para a organização em muitas diferentes maneiras". Segundo a autora, o termo consiste em gerenciar todos os aspectos de design nos dois níveis: no nível de projetos e no nível organizacional. 
Ana Paula Perfetto Demarchi; Cleuza Bittencourt Ribas Fornasier; Rosane Fonseca de Freitas Martins

Hollins (apud BEST, 2006, p.12) descreve a gestão de design "como a organização dos processos para desenvolver novos produtos e serviços" e Cooper e Press (apud Best, 2006) afirmam que a atuação de um gestor de design consiste em responder às necessidades de seus negócios e em dar-lhe uma contribuição para que possibilitem que o design seja utilizado efetivamente.

De acordo com Best (2006, p.17), a gestão de design é ativa em três níveis na organização: estratégico, tático e operacional.

- No nível estratégico, as políticas globais, missão e agenda são definidas. É nelas que o design deve estar ligado. Neste nível, o design expressa visões, valores e crenças da organização, por exemplo, em sua identidade corporativa;

- No nível tático, a equipe, o processo e os sistemas de uma unidade específica de negócio entram em jogo e o design é utilizado taticamente para auxiliar a atingir as metas organizacionais, ajudando, por exemplo, uma empresa para que ela possa conduzir uma auditoria de design quando entra em um novo mercado para benchmark; e

- No nível operacional, no qual o design se manifesta em produtos físicos e tangíveis. É a implementação de projetos e de processos que o cliente pode realmente tocar. O design está presente no dia-a-dia.

No nível estratégico tem-se o líder de design, o qual visualiza como o design pode ser usado na organização. No nível tático surge o gestor de design o qual assegura que o processo de design, de procedimento e funções internas estão adicionando valor à organização, por meio de um time de design definido ou do recurso de design dentro e por meio de um grupo de unidades de negócios e projetos.

Para Best (2006), o final de um projeto de design pode ser um resultado, algo que dê forma a uma estratégia de negócio, porém, design pode ser também um processo de resolução de problema capaz de ajudar a organização a dar forma à estratégia organizacional e molda-la. O nível mais avançado a ser atingido pela gestão de design na empresa é o nível estratégico, no qual o gestor deve, fundamentalmente, criar a relação entre design, estratégia e cultura da organização. O objetivo é controlar a consistência do trabalho do design na organização e introduzir design no processo de formulação da estratégia. É a gestão estratégica de design que esta tese focará.

Gillespie (2002) propõe que se entendam inicialmente os conceitos formativos - design, estratégia e gestão - para então se compreenderem as possíveis combinações, como ilustrado na figura 4.

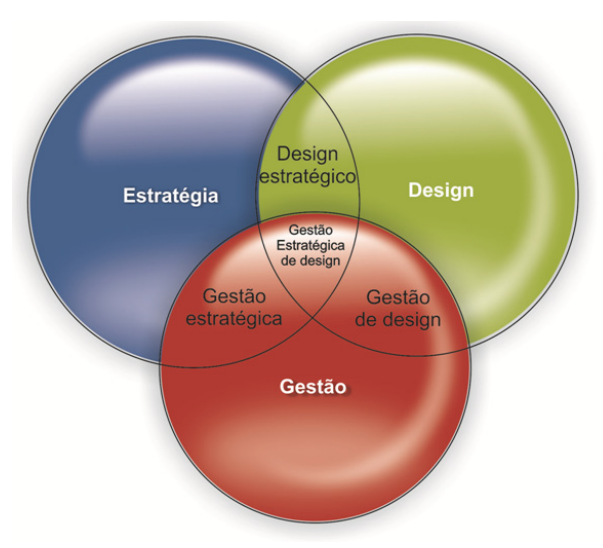

Figura 4- Design, estratégia e gestão

Fonte: Traduzido de Gillespie, B. (2002) 
Gestão de Design humanizada pelo Design thinking a partir de relações conceituais

A palavra estratégia foi sendo incorporada ao ambiente corporativo, e, atualmente, pode ser entendida como "um caminho, ou maneira, ou ação formulada e adequada para alcançar, preferencialmente de maneira diferenciada, os desafios e objetivos estabelecidos, no melhor posicionamento da empresa perante o seu ambiente" (OLIVEIRA, 2005, p.194). Quando a gestão de design navega pela estratégia ela é chamada de gestão estratégica de design.

De acordo com Mozota (2003, p.142), gestão estratégica de design é gerência da contribuição do design para a formulação da estratégia: para definir as responsabilidades e a liderança atribuídas ao design e sua contribuição para a cultura organizacional, busca oportunidades para inovações de design e demonstrações múltiplas de identidade por meio do design.

\section{Considerações finais}

A Gestão de Design, devido às sua base ter sido desenvolvida no paradigma modernista firmou na lógica e na razão, tornando-se até então "engessada". O conceito de design thinking nos últimos anos tem tentado torná-lo mais criativo, inovador, flexível e focado no ser humano, no entanto, a gestão de design se manteve fiel às suas bases administrativas, e apesar de focarem no consumidor, continuam na lógica modernista da Bauhaus, seguindo a Tonica "a forma segue a função".

$\mathrm{Na}$ atualidade, considera-se o mercado mutável e globalizado, que exigirá cada vez mais que a empresa possua um sistema organizacional flexível. As quatro concepções de design relacionadas deixaram de ser concorrentes e tornaram-se complementares. Considerase, atualmente, que o design deva interagir com outras áreas atuantes no processo de desenvolvimento de produtos, integrando a rigidez dos processos organizativos da empresa e a liberdade de criação. Assim, o design torna-se fundamental para garantir a continuidade dos processos e a sedimentação do conhecimento nas organizações como demonstrado na figura abaixo.

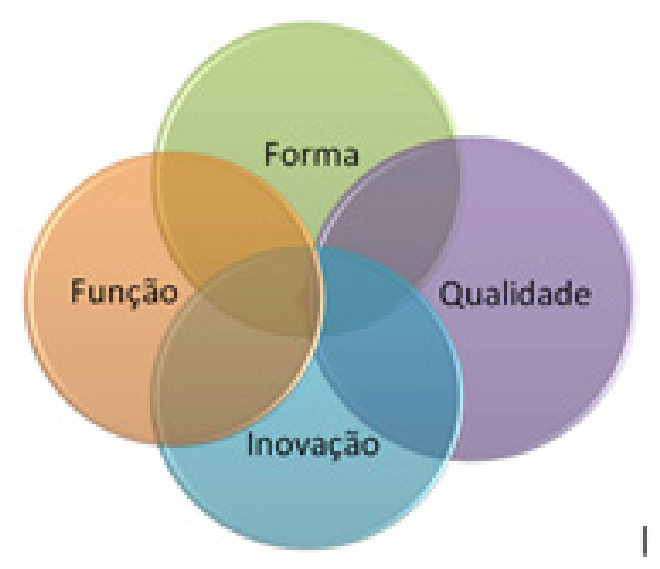

Figura 5- Processos e sedimentação do conhecimento

O Brasil segue agora os passos da Europa e Estados Unidos, que passaram por momentos em que o design era visto como uma ferramenta de desenvolvimento econômico e atualmente esses países retornam o olhar para as questões humanísticas. O problema está no período em que isso ocorreu nesses países, que na década de 50 do século passado, se ajustavam perfeitamente à sociedade modernista em vigência. Hoje deve-se prestar atenção em "acelerar 
Ana Paula Perfetto Demarchi; Cleuza Bittencourt Ribas Fornasier; Rosane Fonseca de Freitas Martins o passo" considerando que a sociedade atual, do século XXI, é exigente, consciente, e autora de seu próprio consumo.

Parece natural que neste contexto, para que a gestão de design se adapte a lógica complexa da sociedade atual, necessita incluir na sua dinâmica o design thinking, no intuito de reforçar a colaboração e flexibilidade necessária para a consolidação da inovação, bem como otimizar habilidades inerentes ao design como a observação empática, a criatividade e a visão do futuro.

O conceito de design thinking traz consigo uma visão mais humanista do design. Com a sua inclusão na gestão de design, ocorre uma reaproximação do design com as questões sociais, que não são mais tendências, mas sim uma realidade de uma sociedade consciente e que presta atenção as essas questões, que se tornaram estratégicas.

\section{Notas}

1 Obra do arquiteto Joseph Paxton.

2 Guilds: tipo de associação comercial que representava diferentes artesãos (MUNARI, 1975)

3 "Muitos estudos relativos à organização de espaços de trabalho e / ou de vendas dependem do design global. Elas pedem, de fato, que se integrem dados correspondentes à organização do local, ao sistema visual, ao mobiliário ou aos quiosques, à iluminação e, certamente, aos produtos ou aos serviços e à imagem da empresa". (SHULMANN, 1994, p.115).

4 Publicação original: HETZEL Patrick em 1993, Design Management et Constitution de l'Offre, Doctorat Sciences de Gestion, Université Jean Moulin, Lyon.

\section{Referências}

ANTAR, Natalie. Cadeira Thonet: 150 anos de história. Casa e Jardim, on-line, São Paulo. Editora Globo. Disponivel em <http://revistacasaejardim.globo.com/Revista/Common/ 0,,EMI9961316940,00-CADEIRA+THONET+ANOS+DE+HISTORIA.html>. Acesso em: jun 2011.

AZEVEDO, Wilton. O que é design. São Paulo: Brasiliense, 1991.

BAHIANA, Carlos. A importância do design para sua empresa. CNI, Senai/DR-RJ, Brasília, DF: CNI, 1998.

BARBUY, Heloisa. A exposição universal de 1889 em Paris: visão e representação na sociedade industrial. São Paulo: Loyola, 1999.

BEST, K. Design Management: Managing Design Strategy, Process and Implementation. Switzerland: AVA, 2006

BÜRDEK, Bernhard E. Diseño: Historia, teoria y prática del diseño industrial. 2. ed. Barcelona: Gustavo Gilli, 1999.

CHOHAN Bhavnish R. Catalysing organizacional inovation through designer mind: exploring the fundamental issues of 'design Thinking' and its sucessful inplementation for organizacional sucess. In: INTERNATIONAL DMI EDUCATION CONFERENCE, 2008, France.

COSTA, Christiane Maria. Análise das relações entre as comunidades envolvidas na identidade do designer. 2002. Dissertação (Mestrado em Tecnologia ) - CEFET, Curitiba, 2002. 
Gestão de Design humanizada pelo Design thinking a partir de relações conceituais COTEC. Diseño e innovación. La gestión del diseño em la empresa. Fundación para la Innovación Tecnológica. Madrid, 2008.

DE SORDI, J. Gestão por Processos: uma abordagem da moderna administração. São Paulo: Saraiva, 2005.

DEMARCHI, Ana Paula Perfetto. Gestão Estratégica de Design com a abordagem de design thinking: proposta de um Sistema de Produção do Conhecimento: 2010. 278 f. Tese (Doutorado em Engenharia e Gestão do Conhecimento) - Universidade Federal de Santa Catarina, Florianópolis, 2011.

DENIS, Rafael Cardoso. Uma introdução à história do design. São Paulo: Edgard Blücher, 2000. DESCHAMPS, Jean Philippe; NAYAK, P. Ranganath. Produtos irresistíveis. São Paulo: Makron Books, 1997.

DROST, Magdalena. Bauhaus: 1919-1933. Berlim: Bauhaus Archiv, 1994.

ENCYCLOPEDIA Britannica. Disponível em:<http://www.britannica.com/EBchecked/media/ 67498/Logo-for-AEG-designed-by-Peter-Behrens-1907>. Acesso em: fev 2010.

GILLESPIE, B. Strategic Design Management and the Role of Consulting. 2002. Disponível em: <http://www.designingbusiness.com/BrianG_SDM_ResearchReport.pdf>. Acesso em: 3 nov. 2008.

HESKETT, John. Desenho Industrial. Rio de Janeiro: José Olympio, 1998.

HOSBSBAWM, Eric J. A era das revoluções: 1789-1848. 5. ed. Rio de Janeiro: Paz e Terra, 1982.

ICSID. Interncional Concil of Societies of Industrial Design. Disponível em <http://www.icsid.org/ static.php?sivu=3>. Acesso em: 10 out 2006.

JOSEPH J. Paul. Performance Metrics to Measure the Value of Design. Design Management Journal, v.11, n.4. Disponível em: <http://www.dmi.org/dmi/html/conference/ europe02/01124GRI10. pdf>. Acesso em: dez. 2003.

LÖBACH, B. Diseño industrial. Barcelona: G.G., 2000.

LOCKWOOD, Thomas. Design thinking: Integrating innovation, customer experience, and brand value. New York: Allworth, 2006.

MAGALHÃES, Cláudio. Design Estratégico: integração e ação do Design. Estudos em Design, v. 3, n.1, jul. 1995.

Design Estratégico: integração e ação do Design Industrial dentro das empresas. SENAI/DN-SENAI/CETIQT-CNPq -IBICT - PADCT - TIB, 1997.

MARTIN, Roger. The design of business: Why design thinking is the next competitive advantage. Boston: Harvard Business, 2009.

MARTINS, Rosane F. de F.; MERINO, Eugenio Andrés D. A gestão de Design como estratégia organizacional. Londrina: EDUEL, 2008.

MOZOTA, Brigite Borja de. Design Management: Using to build brand value and corporate innovation. New York: Allworth Press, 2003.

MUNARI, Bruno. Diseño y comunicacion visual. . Barcelona: Editora Gustavo Pili, 1975. Das coisas nascem coisas. São Paulo: Martins Fontes, 1998. 
Ana Paula Perfetto Demarchi; Cleuza Bittencourt Ribas Fornasier; Rosane Fonseca de Freitas Martins NIEMEYER, Lucy. Design no Brasil: origens e instalação. Rio de Janeiro: 2AB, 1997.

OLIVEIRA, D. Planejamento estratégico, conceitos, metodologia e praticas. 22. ed. São Paulo: Atlas, 2005.

PEVSNER, Nikolaus. Os pioneiros do desenho moderno: de William Morris a Walter Gropius. 2 ed. São Paulo: Martins Fontes, 1995.

PHILLIPS, Peter L. Briefing: a gestão do projeto de design. São Paulo: Edit. Edgard Blücher, 2008.

QUARANTE, Danielle. Diseño Industrial: elementos introductorios. Barcelona: Ediciones CEAC, 1992. v.1.

RIBEIRO, Hélcio Pupo. Artes industriais: do rococó ao funcionalismo industrial. Bauru: Javoli, 1985.

SCHULMANN, Denis. O Desenho Industrial. Campinas: Papirus Editora, 1994.

STRUNCK, Gilberto. Como criar identidades visuais para marcas de sucesso. 3. ed. Rio de Janeiro: RioBooks, 2007.

TAMBINI, Michael. O design do século. São Paulo: Ática, 1997.

THONET CHAIR. Disponível em:<http://alltimmedesign.blogspot.com/2009_11_01_archive. html>. Acesso em: jun 2011.

WALLACE, David. Introdução ao Design. Disponível em:<http://users.skydome.net/ WALLACEDAVID/introd.htm>. Acesso em: maio 2002. 